Meta

Journal des traducteurs

Translators' Journal

\title{
Factors Influencing the Process of Translating
}

\section{Dongfeng Wong et Dan Shen}

Volume 44, numéro 1, mars 1999

Théorie et pratique de la traduction en Chine

The Theory and Practice of Translation in China

URI : https://id.erudit.org/iderudit/004616ar

DOI : https://doi.org/10.7202/004616ar

Aller au sommaire du numéro

Éditeur(s)

Les Presses de l'Université de Montréal

ISSN

0026-0452 (imprimé)

1492-1421 (numérique)

Découvrir la revue

Citer cet article

Wong, D. \& Shen, D. (1999). Factors Influencing the Process of Translating. Meta, 44(1), 78-100. https://doi.org/10.7202/004616ar

\section{Résumé de l'article}

La traduction est un processus complexe, influencé par des facteurs linguistiques, culturels et personnels. Cet article essaie de démontrer que des différences de toutes sortes entre langue et langue, culture et culture et personne et personne constituent la source principale des difficultés de traduction. Une étude systématique de ces facteurs sera sans aucun doute utile pour établir des stratégies efficaces contre leurs influences négatives dans la traduction. 


\title{
Factors Influencing the Process of Translating
}

\author{
dongfeng wong and dan shen \\ South China University of Technology, Guangzhou \\ and Peking University at Beijing, China
}

\begin{abstract}
RÉSUMÉ
La traduction est un processus complexe, influencé par des facteurs linguistiques, culturels et personnels. Cet article essaie de démontrer que des différences de toutes sortes entre langue et langue, culture et culture et personne et personne constituent la source principale des difficultés de traduction. Une étude systématique de ces facteurs sera sans aucun doute utile pour établir des stratégies efficaces contre leurs influences négatives dans la traduction.
\end{abstract}

\section{ABSTRACT}

Translation is a complex process, involving linguistic, cultural and personal factors. This article seeks to show how these factors constitute the main source of translation difficulties. The authors suggest that a systematic discussion of these factors would be useful in establishing effective strategies for avoiding pitfalls in translation between English and Chinese.

Translating, as I. A. Richards claims, "is probably the most complex type of event in the history of the cosmos" (Nida 1993: 1). Many factors are crucial to the process of translating and no explanation of translating can claim to be comprehensive if these factors are not systematically considered. O wing to the great subtlety and complexity of the factors in question, this short paper will not be able to cover all of them exhaustively, so we will focus our attention on key factors in the three most important areas: language, culture and the translator's personal conditions. The following discussion will be primarily concerned with translating between English and Chinese.

\section{LINGUISTIC FACTORS}

Linguistic factors exert a direct and crucial influence upon the process of translating. Each of the linguistic factors, phonological, lexical, syntactic and textual, can interfere with translation. It can safely be assumed that interlingual differences constitute a main source of translation difficulties.

\subsection{Phonological Factors}

At the phonological level, there is no correspondence between English and Chinese. Yet literary translators sometimes do try to create a certain kind of equivalence when they encounter poetic or rhetorical phonological features, for example:

Henhao, buyong danxin le. Wo haiyou weiyuan de fufen ne.

(He gave me very good news. We need not look for trouble. I have the possibility of being a member of the committee!) 
"M oshi de guiyuan?" qizi mei ting qingchu tade hua.

("What's a common tea?" asked the wife, who only vaguely caught the sound.) (Tr. Qian Gechuan)

Here the Chinese word weiyuan (member of a committee) sounds quite like guiyuan (longan, a kind of tropical fruit). In the conversation, the "wife" does not quite catch the word and mistakes guiyuan for weiyuan. If the two words are translated literally, the readers will find the wife's mistake incomprehensible since there is no phonological similarity in English between the two items. The translator therefore resorts to a functional approach, turning longan (guiyuan) into common tea. Now the form is changed, but the function or effect is preserved: common tea is phonologically related to committee. When we admire the translator's creative rendering in this particular instance we have to admit that, in most cases, such homophonic or near-homophonic expressions are untranslatable. A more common practice is to explain the rhetorical significance of such a usage in a footnote.

Chinese is generally referred to as a tonal language because there are FOUR TONES for its characters. Each Chinese character or morpheme phonologically consists of one syllable and one of the four tones. The four tones are illustrated in Figure 1.

Figure 1

\begin{tabular}{l|c|c|c|c}
\hline Symbol & - & $/$ & $V$ & $I$ \\
\hline Chinese term & yinping & yangping & shangsheng & qusheng \\
\hline Meaning & level & rising & falling-rising & falling \\
\hline
\end{tabular}

Here yinping and yangping are termed as PING, and shangsheng and qusheng as ZE. In classical Chinese poetry the four tones are indispensable in forming poetic melody. According to the rule, the patterned sequence of the tones of one line, especially the second, fourth and sixth characters, must be distinctive from that of the next line basically in terms of PING (indicated as "-") and ZE (indicated as "|"):

\footnotetext{
Qinshi mingyue $\mathrm{H}$ anshi guan,

Wanli changzheng ren wei huan.

(The age-old moon still shines over the ancient Great Wall, But our frontier guardsmen have not come back at all.) (Tr. Xu Yuanchong)
}

Organized this way, the poem reads rhythmically with a unique musical flavour. This poetic feature, however, can not be transferred into English, because English words, instead of four corresponding tones, have what we call STRESS. Thus classical English poems are characterized by stress-timed rhythms made up by a patterned combination of stressed and unstressed syllables. A poem created according to English phonological patterns that make it read well would widely be considered untranslatable into Chinese because of its stress-based meter.

Some translators, however, have been trying to build acoustic equivalences in translating poetry between English and Chinese, despite the lack of correspondence 
between the two languages in this respect. One solution is to employ English metric patterns when translating a Chinese classical poem and vice versa in translating an English poem. In the latter type of translation, another well-known strategy sees the Chinese dun (sense group) used to substitute an English foot with the original rhyme preserved.

All these efforts aim at endowing the translation with a regular metric or poetic pattern that makes the poem read like a poem. But it is doubtful that poems transformed in this way really succeed in bridging the gap between the source language $(\mathrm{SL})$ and the target language $(T L)$ in terms of the sound effect conveyed by rhythm.

Another important phonological feature is rhyme, an indispensable element in most metric poetry for which a translated equivalent is not easy to find. The reason is obvious: each rhyming unit has a dual function: (1) expressing semantic content; (2) creating poetic effect through phonological repetition. Since it is very rare that an SL item and a TL item possess identical semantic and phonological values, the translator generally has no choice but to reconstruct the rhyming pattern with sounds different from those in the original. If the translator tries hard to convey the rhyming pattern in terms of sound effects, semantic or aesthetic distortions are often unavoidable. For example,

I was angry with my friend:

I told my wrath, my wrath did end.

I was angry with my foe:

I told it not, my wrath did grow. (W. Blake: A Poison Tree)

A Chinese version goes like this:

Wode pengyou jiaowo qinao,

Wo yishuochulai, wodeqi jiuxiao;

Wode diren jiaowo qifen,

Wo bushuo, wodeqi yuezhang yuemaosheng. (Tr. Bian Zhiling)

$H$ ere the SL rhyming units friend and end, and foe and grow are substituted by qinao (angry) and jiuxiao (got lost), and qifen (irritated) and maosheng (lush). The translator has obviously done his utmost to convey the SL rhyming effect by constructing a new sound combination. But he succeeds in doing so only at the expense of the TL text's coherence; in Chinese, maoshen (lush) and qi (anger) are incongrous, just as in English we would not say my anger became more and morelush. While grow in English can collocate with both plant and anger, zhang (grow) in Chinese can only predicate plant when it goes with maosheng.

Since English and Chinese have almost nothing in common at the phonological level, phonological factors are an inevitable and in most cases unconquerable difficulty in translation between the two languages.

\subsection{Lexical Factors}

The most problematic and time-consuming aspect of translation is achieving an accurate lexical rendering. The marked differences between English and Chinese in this respect present significant difficulties for translators.

Modern English and Chinese have undergone completely different lexical evolutions. English has seen a snowballing of meaning expansion, the tendency to endow 
an old word with a new meaning by means of extension or metaphor. The Chinese lexicon, on the other hand, has expanded primarily through double-syllabling, the tendency to combine two characters or morphemes into one word with a set meaning. These distinct modes of lexical development have given rise to different degrees of contextual dependence. The snowballing mode naturally makes many English words polysemous and hence more context-dependent, while the practice of doublesyllabling makes Chinese words monosemantic and hence much less context-dependent. Seen in this light, it is not surprising that a "familiar" English word can express a totally unexpected meaning when used in a particular context. An English word can vary in meaning drastically according to context, verbal relation, time, place, participants, topic, mode, media, etc. For example, in Chaucerian times, wife meant "woman," and not specifically "married woman in relation to her husband;" similarly in Shakespearean times, deer refered to an animal of any kind, while in modern English it refers specifically to "a kind of fast four-footed animal, of which the males usually have wide branching horns;" likewise, the mouse spoken of by a housewife means something entirely different from the mouse mentioned by a computer user; travellers in an airport and soldiers in a military camp will react very differently to the word Attention!; an Englishman's interpretation of the verb table differs from that of an American; etc. These semantic shifts demand different treatments depending on the target language of translation. If the translator fails to recognize the specific meaning afforded by a particular context, he or she will probably fail to render the passage correctly.

The difference in lexical context-dependence between English and Chinese doubtless present difficulties for translators. Common sense dictates that the more polysemous a word is, the more ambiguous, indeterminate, and hence context-dependent its meaning. Therefore, when translating from English into Chinese, the translator must attach great importance to context and try to make the polysemous words unambiguous with the help of the contextual clues. Many mistranslations are the result of neglecting, ignoring or misjudging the context in which a word is used.

Another closely related problem is the difference in semantic range between English and Chinese. Predictably, the semantic range of a "snowballed" English word is much wider than that of a "double-syllabled" Chinese word composed of two or more semantically independent morphemes, the interaction of which largely stabilizes the meaning and makes it less context-dependent.

Differences and similarities in semantic range can be viewed as a series of semantic relations between the two languages, such as correspondence, inclusion, intersection, parallel, conflict and nil (cf. Liu 1991: 418-420; Tan 1990: 128-139; Nida 1979: 15-20). Strictly speaking, there are almost no synonyms between any two languages, but it is not impossible to build interlingual equivalences or correspondences be tween specific items in specific contexts.

For example, the meaning of the English uncle IN CLUDES the meaning of such Chinese words as shufu (father's younger brother), bofu (father's elder brother), jiujiu or jiufu (mother's brother), gufu (father's sister's husband), yifu (mother's sister's husband), and shushu (father's younger brother or a friend or acquaintance about the same age as a young person's parent). But when unde is used in a particular text, its specific meaning is clarified by the context, enabling the translator to select one of the words listed above. It would be considered a terrible mistake in Chinese culture to 
refer to the father's brother as jiujiu or jiufu. The translator must be bilingually and biculturally competent enough to establish a context-dependent correspondence between English and Chinese in cases of semantic inclusion.

Similar skill is required to deal with INTERSECTION, where the meaning of an SL lexeme partially corresponds to that of the TL. But in particular contexts, CORRESPONDENCE can be established between the SL and the TL.

In a PARALLEL semantic relation, a meaning is expressed in different ways in each language. The English idiom teach fish to swim has a parallel in the Chinese expression banmen nongfu (showing one's proficiency with an axe before Lu Ban, the master carpenter of ancient China). If such parallel expressions are not too culturally specific and the metaphorical meaning involved is not overly creative and novel, they can often be used as equivalents. For instance, the Chinese phrase yuhou chunsun (like bamboo shoots after rain) is often considered equivalent to the English (spring up) like mushrooms. However, it may not be wise to translate the English proverb in the country of the blind, the one eyed man is king into the Chinese Shuzhong wu dajiang, Liao Hua chong xianfeng (i.e. since there is no competent general in the kingdom of Shu, Niao Hua has to be chosen to be the vanguard commander), as the latter originates from a classic Chinese novel and is therefore heavily culture-specific.

In the case of CONFLICT, a pair of conflicting meanings are expressed in the same or similar way, as in "false friends." Take, for example, the Chinese long and the English dragon. Although these two words are traditionally considered equivalent, their connotations and even their referents are in effect quite different. Chinese people view long as a symbol of power or good fortune, while the English sees the dragon as fierce and associate it with evil, cruelty and violence. In order to avoid such negative associations, some Western newspapers and magazines use the term Four Tigers to translate the so-called Yazhou si xiaolong (four little dragons in Asia, a term referring to wealthy countries and regions in Asia such as South Korea, Singapore, Hong Kong and Taiwan).

From another point of view, the connotation expressed by long is NIL to English, just as that of dragon is to Chinese. A relation is NIL when the concept or connotation of the SL item does not exist in the TL. In this case, if the translator uses dragon to translate the Chinese long, he or she runs the risk of misleading the reader. Differences between cultures may mean that one language has expressions and concepts that may not exist in another. For example, in Chinese, we have no ready-made equivalents for the English brunch, punk, hippie, motel, etc., and likewise there are no English equivalents for the Chinese kang (heated brick bed), Guandi miao (temple enshrining Guan $\mathrm{Yu}$, a well worshipped ancient Chinese hero), zongzi (a pyramidshaped dumpling made of glutinous rice wrapped in reed leaves that is eaten during the Dragon Boat Festival), nao dongfang (making mischievous fun of the newly married couple in the bridal chamber on their first wedding night), etc. Faced with such words and expressions NIL to the TL, the translator is hard-pressed to convey the original meaning and is often left with no choice but to "borrow" the original lexical item and add a footnote to explain its meaning.

The lexical and semantic differences between English and Chinese form a major chal lenge to the translator's linguistic judgement and word selection when translating between these two languages. 


\subsection{Syntactic Factors}

English and Chinese belong to different language families and systems. This difference is directly reflected in the way people think, in their syntactic organization, and unavoidably comes up in the process of interlingual transference.

Originating from Old English, which, as a typical synthetic language, was highly inflected, Modern English syntax is still characterized by a degree of inflection. In contrast, Chinese is a typical analytic language, characterized by non-inflection, fre quent use of function words and functional manipulation of word order, through which various syntactic and semantic relations are expressed.

English inflections are concerned with gender, number, case, tense, aspect, voice, mood, person, part of speech and degree of comparison. Thus, whereas an English word can, through inflection, express several grammatical meanings, Chinese, as a non-inflected language, has to form such grammatical meanings essentially by lexical means.

When translating English into Chinese, inflections often lead to misinterpretation and mistranslation since Chinese syntactic norms tend to influence the translator's judgement about how to deal with changes in inflection. All too often, some of the semantic or rhetoric features of a text are lost in the process of syntactic adaptation. For example,

Yet they could easily have learned that there are over hundred registered correspondents in Beijing.

An unexperienced Chinese translator might not recognize the meaning realized by the inflected form could have learned, because Chinese syntax has no equivalent to the English subjunctive mode. He or she might therefore translate the sentence as "... tamen hui liaojie dao..." (... they could... learn...); a correct translation would require support by lexical means, i.e., adding a lexeme to convey the meaning originally or something like that.

Interestingly, when translating Chinese into English, the translator has to go through a converse process: first recognizing the grammatical meanings expressed or implied in the lexical expressions, and then reorganizing these relations according to English syntactic norms.

With the use of inflections, English sentence tend to have strict and compact syntactic structures. In addition, there are a wealth of conjunctions, prepositions and a developed system of pro-forms, which can incorporate and interconnect a number of clauses through subordination into a complex long sentence. The structure of such a sentence, often likened to a tree, is termed hypotaxis and is characterized by formalized relations in which words, phrases, and clauses are closely connected.

Devoid of inflections, Chinese tends to use syntactic order and lexical means to express grammatical meanings. The meaning of a sentence unfolds word by word or clause by clause, in a coordinated shape that has few of the overt connections seen in English. This diffusive mode of construction, often likened to a stream or length of chain, is termed parataxis and features covert connectivity, whereby words, phrases and clauses are organized according to natural temporal-spatial and logical sequence. There are far fewer connective devices than in English, and hence the word order in a Chinese sentence is not so flexible as in English. 
Accordingly, in translating between English and Chinese, the translator has to take the trouble to interpret and then reconstruct the SL structure on the basis of TL syntactic norms. When translating English into Chinese, many English connective devices will disappear and their functions will often be substituted by lexical means or be accomplished through meaningful ordering, coordinated on the surface but subordinate in deep structure:

If he won't come here, I'll not go there.

Ta bulai, wo buqu.

(word-for-word back-translation: He not come, I not go)

It is not surprising that in translating between these two languages, the translator is constantly adaptating long and short sentences, overt and covert relations, "tree"and "stream"-like constructions, and so forth. This is not an easy task.

As far as word order is concerned, the most prominent difference between English and Chinese is that English has postmodifiers and Chinese does not. An interesting phenomenon arises: postmodifiers are normally considered unmarked in English but are unacceptable or, at the very least, must be marked in Chinese. That is why almost all the English postmodifiers should be turned into Chinese premodifiers followed by the modifier marker de, or be translated using some element other than a modifier.

Differences in word order between English and Chinese can also be seen in interrogative structures, but these normally present little difficulty because the transfer becomes more or less automatic, as is the case with other structures involving conventional grammatical inversion. However, it must be noted that although reordering in translation is often necessary it is also dangerous in terms of thematic prominence (see 1.5. for more discussion). When part of the sentence meaning, or thematic meaning in Leech's term (1983: 19), is dependent on the order, a random change to the order will lead to the loss of that meaning or thematic prominence, e.g.

I like Danish cheese best.

Danish cheese I like best.

It's Danish cheese that I like best. (Leech 1983: 20)

The three sentences share the same conceptual meaning but the thematic values vary in terms of emphasis and focus. Each should be treated differently as the following (with the word-for-word back-translations in brackets):

Wo zui ai chi Danmai rulao.

(I best love eat Danish Cheese.)

Danmai rulao wo zui ai chi.

(Danish cheese I best love eat.)

Wo zui ai chi de shi Danmai rulao.

(I best love eat de is Danish cheese.)

The strategy is simple: substitute the syntactic order in the original with an equivalent TL syntactic order that carries the same or similar thematic meaning or prominence.

Syntactic differences between English and Chinese are a big topic, requiring a book-length study. The purpose of the present discussion is just to hint at how syntactic factors influence the process of translating. 


\subsection{Textual Factors}

A text is constructed on the basis of individual sentences, so translation problems in realizing thematic structure and connection are similar to those encountered at the syntactic level. The textual difference between English and Chinese results largely from syntax, and the central problems here are therefore still order and connection, only within a larger framework or at a higher rank.

\subsubsection{Thematic organization}

The importance of thematic organization is often neglected in translation. Interestingly, many translation textbooks in China include a section on the methods of translating passive-voice sentences, in which two main alternatives are suggested. One is to make a direct transfer and the other is to turn an SL passive-voice sentence into Chinese by reversing the original order, i.e. putting the Actor back in the position of subject and the Goal in the position of object. In many cases, a sentence translated either way may appear equally appropriate, but when such instances occur in a continuous text, the reversion of the SL order often runs the risk of changing the original thematic values concerning textual coherence or rhetorical significance. Suppose the order of all passive-voice sentences in an SL text that employs the structure frequently is reversed in translation, with all the themes turned into rhemes. What will happen? The chain of textual coherence will be badly affected by the disruption of the thematic progression. For example,

$H$ is figure was enveloped in a riding cloak, fur collared, and steel clasped;...

In isolation, this sentence can be reversed in Chinese as "A riding cloak... enveloped his figure" with no harm done. But when this sentence appears in a continuous sequence, it is another story:

I could see him plainly. His figure was enveloped in... (C. Bronte: Jane Eyre)

In this context, if the translator reverses the original order, textual connectivity or thematic progression will be seriously affected. It is therefore no coincidence that, in Li Jiye's and Zhu Qingying's versions of Jane Eyre, neither uses reversion to present this sentence. Actually, an SL passive structure can potentially be rendered in either original or reversed order without the thematic values being affected. But the textbooks should also discuss the possibility of inappropriateness in some textual situations when introducing such a method. Unfortunately, this is something many textbooks have failed to do.

Thematic organization works to provide the text with a structural framework which relates back to the writer's main intention and provides perspective on what follows (Brown \& Yule 1983: 143). A sentence expressed in a particular theme-rheme arrangement has a unique communicative value and plays a distinct textual role in the network of the given-new development of information. So, randomly shifting the order, especially "the initial position in a sentence, paragraph, or section [...] with the final position being second in importance" (Nida 1993: 83), may distort thematic prominence or eliminate the original thematic significance. As well, local thematic deviations may jeopardize the continuity or coherence of the text being translated. 
In a word, the SL thematic organization should not be ignored, because it often takes on important stylistic values and may play a very important role in the representation of the writer's intention. However, the translator should not be overcautious about it, since his or her priority usually goes to conveying semantic content and conforming to TL syntactic and textual norms.

\subsubsection{Cohesion}

At the textual level, cohesion refers to semantic relations between sentences. These relations are expressed through cohesive ties, which are the linguistic resources that help establish cohesion based on grammar or vocabulary, such as reference, substitution, ellipsis, conjunction and lexical cohesion (Halliday \& Hasan 1976).

Cohesion can present difficulties in translation because of differences in this respect between languages. As grammatical difference is universally greater than that of vocabulary, with the exception of idiomatic expressions and certain culturallybound items, so cohesion achieved through grammatical devices may have more impact on the interlingual transfer than cohesion achieved by lexical means. The cohesive ties that are more or less connected with grammatical representation include reference, substitution, ellipsis and conjunction.

As mentioned in 1.3., English is characterized by a developed system of proforms and a wealth of conjunctions, while Chinese is much less rich in these aspects. Accordingly, the occurrence of pro-forms and conjunctions is much rarer in Chinese texts. This means that a number of English pro-forms and conjunctions have to be replaced by other forms in a Chinese translation. The cohesive devices involved in this process include reference, substitution and conjunction.

Dealing with ellipsis is more complicated. Although ellipsis appears both in English and Chinese, serving the same syntactic and textual functions, the respective syntactic, textual as well as stylistic norms are quite different. English syntax dictates avoiding simple repetition if there is no rhetorical motivation involved. The norms of modern Chinese, however, prefer substantial representation. Not that ellipsis is rare in Chinese-it is actually quite common-but what is conventionally omitted in Chinese is often not tolerable in English, such as the continuous omission of subjects. So, in spite of the common occurrence of ellipsis in both English and Chinese, the possibility of making a direct transfer remains very slight. Ellipses are thus often replaced by other cohesive devices such as reference, substitution or lexical repetition when translating between English and Chinese, e.g.,

She kissed me, and I her... (C. Bronte: Jane Eyre)

When translating this sentence into Chinese, the italicized part must be rendered as "I also kissed her." Apparently, the cohesive tie the Chinese translator tends to use in this case is lexical repetition. Consider the following two lines of a classical Chinese poem with a word-for-word back translation in the brackets:

Xiaojing danchou yunbin gai,

(Morning mirror worry cloud-hair change,)

Yeying yinjue yueguang han.

(Evening chant should feel moonlight chill.) 
In this poem, the subject is omitted. This ellipsis, however, would not be acceptable in English. The following are the three English versions:

(1) Before the mirror, you will fret to find those cloudlike tresses changing Making rhymes at night, you'll find the moonlight has grown chill. (Tr. Zhang Tingchen \& Bruce M. Wilson)

(2) At dawn she'd be afraid to see mirrored hair grey;

At night she'd would feel cold while I croon by moonlight. (Tr. by Xu Yuanchong 1988)

(3) At dawn I'm grieved to think your mirrored hair turns grey;

At night you would feel cold while I croon by moonlight. (Tr. Xu Yuanchong 1992)

The semantic indeterminacy caused by the ellipsized subject in the original poem obviously challenges the translators' interpretation. According to English textual norms, the cohesive item to be added here should be reference, however the appropriate referent is hard to determine.

Another cohesive device in Halliday and Hasan's model is lexical cohesion. Though it involves more variables than the others, it causes fewer translation difficulties because the norms for using this device are much the same in English and Chinese: where there is semantic equivalence lexically, there is usually correspondence of lexical cohesion textually.

On the whole, textual factors act on the process of translating mainly in the two ways described above. If the translator does not have a clear idea of the differences between the SL and the TL in terms of the various devices and mechanisms used to achieve cohesion and coherence, he or she will not be able to establish functional equivalence on the textual plane and the translation will likely suffer as a result.

\section{CULTURAL FACTORS}

According to the Sapir-Whorf hypothesis, different linguistic communities have different ways of experiencing, segmenting, and structuring reality (see Gorlée 1994: 105). Translating works to bridge the cultural gap between two worlds and make communication possible between different linguistic communities. Bassnett likens language to "the heart within the body of culture," pointing out that "the surgeon, operating on the heart, cannot neglect the body that surrounds it, so the translator treats the text in isolation from the culture at his peril" (Bassnett 1992: 14).

In the previous section, we operated on the "heart," so to speaks now we will turn to the "body."

Edward Sapir claims (1956: 69):

No two languages are ever sufficiently similar to be considered as representing the same social reality. The worlds in which different societies live are distinct worlds, not merely the same worlds with different labels attached.

Translating, which involves two languages, is unavoidably influenced by two cultures, the source culture (SC) and the target culture (TC). The following discussion will look at how both intercultural and also intracultural factors influence the translation process. 


\subsection{Intercultural Factors}

According to Catford (1965: 94), instances of untranslatability can arise from two sources: one is linguistic, and the other is cultural. A translator who fails to take the cultural context into account is likely to commit some ridiculous errors. The very existence of a cultural gap can act on the process of translating by interfering with the translator's logical judgement and linguistic selection.

\subsubsection{Culture-specific expressions}

Lotman claims "No language can exist unless it is steeped in the context of culture" (see Bassnett 1992: 14). In Language, Culture and Translating, Nida expresses the same idea in another way (1993: i),

The role of language within a culture and the influence of the culture on the meanings of words and idioms are so pervasive that scarcely any text can be adequately understood without careful consideration of its cultural background.

It is true that different peoples live on the same planet in relatively similar material surroundings and that each language contains expressions to describe this material world-sun, river, rain, mountain, father, etc. But through long and unique evolution, each culture develops distinct conceptions about the world. As well as the common core expressions which are mostly conceptual or denotative, each language has myriad of culturally-specific expressions that are full of associations for that people.

Thus the same object can be conceptualized or symbolized with different cultural "colours" or "flavours." For example, in the eye of Western people, "the pale white band of stars and clouds of gas that can be seen across the sky at night" is M ilky Way, while to Chinese people it is yinhe (silver river). The two phrases refer to the same object, but they have different associations arising from distinct cultural identities. When Western people pray for another person's luck or fortune, they will say God bless you, while old Chinese people tend to say Pusa baoyou (Buddha bless). Here the meaning the speaker wants to express is the same, but different cultures will resort to different means of expression. The case is referred to by Lado (1957: 118) as "same meaning, different form." Since these forms are very often culture-specific or at least culture-coloured, some argue that they should not, culturally speaking, be considered substitutable. Thus, although the English M ilky Way is often used as an equivalent of the Chinese yinhe, when M ilky Way is used as the starting point for an extended metaphor, it would be awkward to substitute the image by silver river in translation. For example,

(1) See yonder, lo, the galaxye which men clepeth the Milky weye,

For it is whyt, which men in England

Do call Watlyng Street. (Chaucer: H ous of Fame)

(2) A broad and ample road, whose dust is gold

And pavement stars, as stars to thee appears

Seen in the galaxy-that M ilky way,

Thick, nightly, as a circling zone... (M ilton: Paradise Lost) 
It seems very natural for poets to liken the M ilky Way to a street and a road with dust and pavement. However, if M ilky Way is replaced as Chinese yinhe (silver river), these images become inappropriate.

The following are English versions from two Chinese classical poems:

(3) Passing an uneven pass I come aboard the boat

UP into the Milky Way,... (Tr. Wu Juntao)

(4) A thousand starry sails dance in the fading M ilky Way. (Tr. Xu Jieyu)

Reading these poems, Western readers will most likely be puzzled: How can boat and sail go along the M ilky Way? In such cases, a literal translation accompanied by an explanatory footnote is recommended. Because of the importance of culturalcolouring, it is generally not considered desirable to render such idioms as teach fish to swim into something like "to show one's proficiency with an axe before Lu Ban," or in the country of the blind, the one-eyed man is king into something like "since there is no competent general in the kingdom of Shu, Liao Hua has to be chosen as the vanguard commander" (see 1.3).

Another type of cultural difference Lado distinguishes is "same form, different meaning" (1957: 114). The so-called "false friend" usually comes from this type. Since the "forms" of the related items are the same, they are often misleading. For example, the brand name of a well-known Chinese battery baixiang is literally translated as White Elephant. However, the translation elicits unfavourable reactions from English consumers, who use white elephant as an idiom to mean something costly but useless, whereas baixiang means fortune or good luck in Chinese. The connotations involved in each expression are culturally specific, so they should not be used as equivalents. The following pairs provide further examples of "same form different meaning:"

\section{English \\ Child's play \\ (something easy or unimportant) \\ eat one's words \\ (take back what has been said)}

\author{
Chinese \\ erxi \\ (irresponsible attitude toward something) \\ shiyan \\ (break one's promise)
}

If such items are translated literally from English into Chinese or vice versa, semantic distortion is unavoidable.

How a translator treats such culture-specific expressions is a matter of individual judgement, and a number of satisfactory solutions are generally available. The ability to recognize the cultural connotations behind the "form," however, is a reflection of the translator's bicultural competence, which is no less important than his/her linguistic competence.

\subsubsection{Aesthetic differences}

There is a Chinese saying, "Everybody has a beauty-loving heart." But people of different cultures see beauty in their own unique ways. What is beautiful to one culture may not be especially beautiful or may even appear ugly to another.

The aesthetic norms of a given culture reflect how people think. It has been observed that Chinese people tend to think through images because of the influence of their old pictographic writing system (Guan 1995: 104), while Western people are 
accustomed to thinking through logic because of their highly abstract and formalized language system. These thinking modes act directly on people's aesthetic orientation in writing. Chinese writers tend to produce texts full of images in order to render them lively and vivid. A Chinese text promoting tourism cited by Duan (1992: 27) demonstrates this image preference. Describing a Dragon-boat festival, the text is full of highly metaphorical expressions, similes, metaphors, hyperboles, parallelisms, and the like. To a Chinese reader, it is beautifully written. But a literal translation into English may not evoke the same response. The following is an extract from the translation:

The lithsome dragon-boats appear on the river as though the stars twinkle in the Milky Way. The richly decorated pleasure boats look like a scene of mirage. The splendent [sic] awnings in green and gold chain into a palace of crystal. Is this a fairy-land or a mere dream? Looking above, you can see the beautiful doves flying about. Looking below, you can see the sailing lamps glittering.

When this translation is shown to a foreign reporter, his reaction is negative: "full of hyperbole," incomprehensible and ridiculous (Duan 1992). Here, efforts to pursue beauty attract a negative reaction. Obviously, the translational strategy fails to serve the text's purpose. The aesthetic presentation in the original reflects stylistic norms of a specific Chinese genre. The correct practice is to translate it according to analogous stylistic norms in the TC. Since aesthetic standards and norms differ from culture to culture, the translator should have a clear idea about where the difference is and how it should be treated, so that the TL reader might have an analogous, or at least not negative, aesthetic reaction. If the translation produces a negative effect, no matter how faithful it is, it is a failure in both aesthetic and pragmatic terms.

In the example above, uniformity, represented by a series of parallel structures, reflects another aesthetic preference of Chinese writers and readers. This preference for uniformity is deeply rooted in Chinese culture and often influences the translator's lexical and syntactic selection in translating from English into Chinese. This influence is evident in any number of cases where English words and clauses are rendered into four-character Chinese phrases and parallel clauses. This practice has given rise to a long and heated controversy, centering on the point that such a strategy, laden with heavy cultural identity, might "beautify" or assimilate the original expressions. Given the traditional "master-servant" notion of translating, it is a doubtful practice.

Another aesthetic factor which should not be ignored is the difference in literary norms between the SC and the TC. Such differences not only underly divergent styles of representation, but also mould the distinct methods of writing and eventually shape the unique aesthetic values in the two cultures concerned. If one is familiar with the tradition of Chinese classical fiction, or specifically, if one has read the four famous Chinese classical novels Honglou M eng (A D ream of Red M ansions), Sanguo Yanyi (Three Kingdoms), Shui Hu Zhuan (Outlaws of the Marsh), and Xiyou Ji (Journey to the West), all of which are zhanghui xiaoshuo (chapter novels, characterized by a couplet heading at the start of each chapter giving the gist of its content), one will understand why the translator Su Manshu added a couplet heading before each section in Hugo's Les M isérables. For instance, in the Second Book, the first section entitled The Night of a Day's Tramp is substituted by a couplet meaning In Digne a 
Traveller got into Trouble; At Croix de Colbas the Inn-host was M erciless (Su 1903: 672). Su's treatment is determined by an understanding of his readers' aesthetic habits. In his time, the novels familiar to Chinese readers were almost all so-called chapter novels; the introduction of a new mode of story-telling might not have met the readers' aesthetic expectations and might therefore have been resisted. A similar concern is reflected in Lin Shu's translation of Dumas fils's La dame aux camélias and Lin's contemporary Yan Fu's translation of Huxley's Evolution and Ethics, in which the original first-person narrators je and I are respectively substituted by Zhong M a (i.e. Dumas fils) and He Xuli (Huxley). The reason for this replacement is the fact that Chinese readers at that time were unaccustomed to first-person narration, and the translator chose to cater to the readers' preference even at the expense of the aesthetic flavour bestowed by the narrative point of view in the ST. What's more, in Fu Donghua's translation of Gone with the Wind, some long stretches of psychological description were purposefully omitted. Similarly, in Lin Shu's translation of David Copperfield, a 127-word description of the "doctor" in the first chapter is summarized in two short clauses of only eleven characters. These omissions were made because long stretches of psychological and character description were not popular in early 19th century Chinese novels. The translators feared that direct transfer might not conform to the readers' aesthetic expectations and would therefore work against the aesthetic values of the original works.

These instances demonstrate how aesthetic differences affect the process of translation. A translator, as an individual in a specific culture, is sure to be influenced by the aesthetic traditions established in that culture. In a sense, culture itself is a huge text composed of various individual texts, the interrelation of which constitutes intertextuality. Whether one is a writer or a translator, the formation of one's aesthetic preference and writing style is largely determined by this unique intertextual situation. No literary translation can claim to be unaffected by the influence of aesthetic culture.

\subsubsection{Political interference}

The "political culture" (Hulpke 1991: 71) of a specific society al ways exercises certain constraints on the process of translating. These constraints, however, vary from society to society and from period to period. The more political tension there is, the more the translation of politic texts is constrained, either by government censorship or by the translator's own political awareness.

In a politically sensitive society, the translator generally makes a conscious effort to avoid causing uneasiness or irritation among government or the dominant political force by introducing political views considered threatening to the established political culture. According to Hulpke's report, in early 19th-century monarchic Germany, certain politically sensitive descriptions in the translation of Washington Irving's story Rip Van Winkle were purposefully adapted in the interests of the political culture of the time. In a translation published in 1819, the portrait of "George the Third" was changed to "George the Second" and correspondingly "the feats of "heroes of seventy-six' are moved back in time to 1770" (1991: 73). Hulpke observes that the "consequence" of "this slight chronological shift [...] is the same as that of the translational exchange of the two Georges: The German reader's attention is diverted from 
the date of that anti-royal manifesto, the Declaration of Independence." The "exchange of the two Georges and the shift from 1776 to 1770 [...] can be tentatively interpreted as an attempt to eliminate everything that might remind the German reader of a successful revolution" (1991: 73). Hulpke goes on to note that such "a translational strategy might indeed be the result of censorship considerations" (1991: 74).

In a politically tense society, individuals, and especially intellectuals (including translators), are more or less politically minded and respond to the established political culture according to their respective political stances. Examples can be found in the translations of the early 1900s, when China was at the crossroads of feudalism and democracy. In his translation of Cervantes's Don Quixote, Lin Shu, upholding feudal values, uses the translation to propagate vicious innuendoes, not found in the original, about the democratic movement; he even turns his innuendoes into a direct attack in a footnote, to be sure that his intentions are understood by his Chinese readers. In one instance, he changes the meaning of "M ay God damn you knights" into si cideng xiake, zaifa yi pianshou er zhu, buliu yiren yihai shehui (i.e. Knights as such should all be beheaded according to the law and none of them can be pardoned so that they might do no harm to the society). He then adds, in a footnote, "the same to those party members (referring the revolutionary members led by Sun Yat-sen)" (Ma 1984: 309). The same strategy but opposite political intentions are found in Su Manshu's translation of Hugo's Les misérables. Su represented democratic forces, and added things to his translation to publicize his political viewpoint. He goes even farther than Lin by creating a new character named M ingbai (meaning "clearminded"), who calls himself $\mathrm{N}$ ande (implying "a clear-minded man rarely found") to express his sympathy with Jean Valjean and launch a bitter attack against CHINESE feudal values, such as the doctrines of Confucius and M encius. The meaning of one such comment uttered by this character reads:

The slave's doctrine given by Confucius in China can only be obeyed as an infallible law by those contem ptible Chinese wretches, shall we noble French citizens have to listen to the hell of his nonsense? (Su 1903: 698)

Generally speaking, a professional translator will not ask for trouble by introducing ideas that seriously conflict with or threaten the political culture he or she belongs to. When encountering a passage that would be unfavourably received by the political culture or the translation's target audience, the translator may neutralize it or simply leave it out. More often, a text humiliating or threatening to the political status quo of the TC never enters the process of translation at all.

\subsubsection{Ethical influence}

Every society has an inherited ethical system which guides people's behaviour and shapes their moral standards. Usually, the ethical culture of a specific society is characterized to a certain degree by exclusiveness, and cannot tolerate threats from what it regards as unethical or immoral elements introduced by a foreign culture. The degree of ethical tolerance varies between cultures and even between subcultures and different periods. The more conservative the culture, the more ethically exclusive it becomes. 
China's feudal history endured more than 2000 years until 1912. The long-term dominance of feudal culture resulted in an ethically conservative and sensitive society, in which relationships between superior and subordinate, parents and offspring, husband and wife, man and woman, and friend and friend, were subject to strict and clear-cut ethical standards. By comparison, Western cultures are more tolerant. This imbalance will have some degree of influence on the translator's strategic selection. How much depends upon the ethical openness of the TC. In a more open TC context, the translator may be more SC-oriented; otherwise, he or she may be more TCoriented.

Take for instance the Chinese translation of Haggard's Joan Haste in the early 1900s. This novel was first translated by Pan Xizi around 1900. M any descriptions of the love affairs between the heroine and the hero were deleted in this version. One of the most notable deletions was of Joan's illicit pregnancy, considered the most unpardonable sin for a woman at that time in China, when even choosing one's own spouse was condemned as heretically immoral. Such an ethically adapted version was warmly welcomed by contemporary critics, and Joan, the heroine, was honoured as a "chaste" "goddess." Several years later, Lin Shu published his version, which included the ethically dubious passages. Now the "chaste" "goddess" became a "nasty, shameless, mean" woman in the eye of the critics, and the translator himself was bitterly criticized by defenders of feudal ethical norms (See Yin 1907).

China has now become far more open, but Chinese people still cherish their deep-rooted ethical values and moral standards, and still will not tolerate lurid sexual scenes in literary works. Deletion and summarization, neutralization and archaization are still used by translators to treat explicit sexual scenes or sexual taboos.

Besides sex, violence and crime are also contrary to the ethical values of most societies. But interestingly enough, people seem to be more tolerant of translations of violence and crime in literature, and translators make far less effort to adapt descriptions to the ethical norms of the TC.

Another problem worth mentioning is cultural misreading caused by translation, which also results from cultural differences. A translator may replace an SL item with a TL item which he or she considers equivalent but which actually denotes quite different cultural values. The translator's misreading may distort the original writer's intention and culturally mislead TL readers. In translating Shakespeare's King Lear, for instance, Zhu Shenghao, the most famous translator of Shakespeare in China, renders the recurrent word nature as xiao (i.e. something like "filial piety") in many places. It should be pointed out that xiao is one of the strongest ethical conceptions of Confucianism, and is so culturally specific and has ethical connotation so different from those of nature and love used by Shakespeare that Chinese readers would be culturally misled. This is a typical case of cultural misreading in translation.

\subsection{Intracultural Factors}

Cultural differences between regions of a country, or between time periods can also act significantly on the process of translation. Intracultural factors often lead to stylistically or even semantically distinct translations of the same source text. The most influential factors in this case are the strategic orientation and period style within the TL culture. 


\subsubsection{Strategic orientation}

The strategies in question refer to the translational methods, or in a broad sense, the problem-solving methods habitually and conventionally accepted in the TC.

With the progress of science, people's understanding of the real world becomes more and more effective. Each step of scientific development is accompanied by some more thorough understanding and hence a set of more efficient problem-solving strategies. Looking back in history, problem-solving strategies can be seen to vary from period to period. So is the case with translation. Historical studies show that from the very beginning of translation history, two main strategies, i.e. literal translation and free translation (cf. Shen 1989), have been employed. Under the influence of critics' evaluations, writers' comments, readers' reactions, theorists' criticisms, and most importantly, the success of certain translations, competition between these two strategies has been maintained. Sometimes one would take the lead, sometimes the other, and at moments they were neck in neck. These strategic trends directly influence how a translator operates. While it is true that almost no translation of a literary work has adopted a completely literal or completely free strategy, the translator's strategic orientation, developed from his or her culture, makes the resultant product either more literal or more free.

Whether they admit it or not, Chinese scholars view the world according to a deep-rooted principle, namely zhongyong or "the golden means" of the Confucian School. It states, in essence, that one should avoid going to extremes. This culturespecific outlook underlies the fact that Chinese translators are content to hover around the borders of literal and free strategies. Those who disregard the doctrine of the "golden means" are likely to be condemned by critics. The free translation of Les misérables by Su M anshu mentioned in 2.1.3, for example, met with severe attacks by theorists and was later extensively revised by his partner Cheng Duxiu.

Strategies employed by a successful translator can influence other translators' strategic orientations. A typical case is the overwhelming success of Yan Fu's translation of Huxley's Evolution and Ethics in 1897. In the Preface he discusses three aspects difficult to achieve in translating: xing, da and ya, i.e. faithfulness, smoothness and elegance. The book's success, however, turned his "three difficulties" to "three criteria" or three strategies. Recent studies have shown that his success was largely due to his strategy of ya (elegance), which is very important in traditional Chinese literary and aesthetic theory and is hence culturally specific. This strategy, in Yan's opinion, should make use of archaization. He knew that his target readers were all feudal intellectuals who would refuse to read anything without such an archaizing-based ELEGANCE. Consequently, his strategy worked and was then picked up and even abused by others. Since it is traditionally argued that faithfulness and elegance cannot be achieved at the same time, Chinese translation history has witnessed a centurylong controversy of ELEGANCE versus FAITHFULNESS. This controversy actually reflects the battle between literal and free translation strategies. Those who favour ELEGAN CE are also more freedom-oriented while those who do not are more literaloriented. Thus the same original work will appear in several versions with distinct aesthetic effects by translators with different strategic orientations. This point will be discussed further in 3.2.3. 


\subsubsection{Period style}

Styles of writing differ from period to period. What we call a period style results from the prevailing stylistic orientation in writing during a specific period of history. In some cultures, changes in period style are conspicuous, while in others, they are less obvious. Chinese culture saw a drastic change only decades ago. The change was so drastic that many texts written at the beginning of this century are now considered archaic, and have even become incomprehensible to many young people. A number of older writers are still writing poems, letters and essays in classic Chinese, however, and many older translators still can write classic Chinese well. Since classic Chinese has enjoyed a long and splendid literary history, the deep-rooted influence of its special aesthetic and stylistic values cannot be underestimated, and continues to affect Chinese translators' stylistic and linguistic selections. Even now, many Chinese translators like to put some archaizing elements into their products, either short parallel clauses, four-character phrases, or some other archaic expressions. A historical study of Chinese translation shows that the controversy over the appropriateness of archaizing in translation has been going on for about a century. We might predict that long into the future, Chinese translators will still pause before such a selection, and classic Chinese will continue to exert an influence on the aesthetic values of translations from foreign languages into Chinese.

\section{PERSONAL FACTORS}

What we are discussing here are translations done by human beings, not machines. The translator's professional and psychological conditions may therefore have a direct influence on the translated text. The personal factors in question, which account for many of the differences between various translations of the same source, are subtle and complex. They play a crucial role in translating and can be classified into two main types, i.e. personal competence and personal attitudes.

\subsection{Personal Competence}

It is a given that a translator has to be competent in SL interpretation and TL representation, and has to have special knowledge and experience in the field concerned.

In terms of SL interpretation, a translator must be sufficiently competent to understand the various conceptual, associative or thematic meanings of the original. Accurate translation demands perfect interpretation that is based on the translator's command of the SL and understanding of SL culture. Many cases of mistranslation have resulted from the translator's inaccurate interpretation, which are attributable to his or her limited competence in the SL and SC.

As regards TL representation, a translator must be capable of effectively representing in the TL what he or she has interpreted from the ST. That is to say, he or she must be able to find or establish in the TL "the closest natural equivalent" of the SL message (Nida 1966: 12). This competence requires not only a perfect command of the $T L$ and $T C$, but also the ability to write in various styles in the $T L$, in accordance with both the stylistic requirements of the ST and corresponding stylistic norms in 
the TC. It is inconceivable that a person who cannot write effectively in the TL can produce an aesthetically acceptable translation.

In addition to competence in both SL interpretation and TL representation, "translators usually specialize in one or more areas of knowledge in which their competence is needed [...] e.g. aeronautics, accounting, international law, medicine, or agronomy" (Nida 1993: 135). If the translator does not have a basic knowledge of the ideas in the text to be translated, especially technical texts, the work cannot be expected to be satisfactory. For a literary translator, an encyclopaedic knowledge is so crucial that it should be regarded as prerequisite to translating since literature is such a vast vessel of human knowledge. A good translator should be equipped with a wide range of knowledge as well as one or more areas of specialized knowledge. For instance, a literary translator should be well aware of the norms of various literary genres and the functions of various rhetoric devices. In terms of the translation of prose fiction and drama, the former is meant to be read while the latter is performed, and the translator must choose distinct strategies on the basis of their different practical purposes and aesthetic values.

Finally, experience also plays an important role in translating. Only experienced translators can skilfully and organically bring their competence and knowledge into play in SL interpretation and TL representation. Experience can overcome many difficulties, which is why "translation experience" is often one of the requirements listed in translation job postings.

\subsection{Personal Attitudes}

Attitudinal factors involve the individual translator's subjective orientations within a certain historical and cultural context. Even with the same personal competence, two translators with different attitudinal orientations, whether aesthetic, communicative, strategic, political, ethical, or professional, will produce very different translations.

\subsubsection{Aesthetic attitudes}

Aesthetic attitude is reflected in the way the translator interprets the $S L$ text and then represents it in the TL. Some translators may focus their attention on the aesthetic value of the original content, others on its form; some may represent their interpretation through archaism, others through more modern expressions. One may give precedence to the writer's artistic style, another to his or her own aesthetic preferences. An original text will assume different forms and take on different aesthetic values in different versions.

On the one hand, the translator's aesthetic attitude is more or less influenced by the general aesthetic orientations of the historical-cultural context. This accounts for the similar aesthetic selections made by translators of the same period, such as Lin and Yan's common use of the first-person narrator around 1900 (see 2.1.2).

On the other hand, the individual translators' unique understandings of art and aesthetics, as well as their personal aesthetic preferences, diversify their aesthetic orientations and the choices they made in translating. This leads them to make different aesthetic selections for the same source text: while Su translated Les M isérables by adding a couplet heading to each section, following the literary and aesthetic 
conventions of the Chinese chapter novel (see 2.1.2), his contemporary Lin demonstrated more respect to the aesthetic values of the original; his translation of David Copperfied contains no such couplet headings.

Differences in translators' aesthetic values can also be seen in translations of poetry. For example, the several Chinese versions of Byron's The Isles of Greece clearly illustrate the translators' different understandings of how this poem should appear in Chinese: Su Manshu, Ma Junwu and Hushi considered the form of Chinese classical poems appropriate, while Liang Ch'i-ch'ao, Bian Zhilin and Yang Deyu attempted to represent it in modern Chinese free verse. Interestingly enough, in choosing classical forms, Su preferred the five-character poem, M a favoured a seven-character pattern, and $\mathrm{Hu}$ chose lisao style (another form of Chinese classical poem). On the other hand, in adopting modern expression, Liang focused his efforts on rhyming, while Bian and Yang substituted the English feet by Chineseduns (see 1.1) with the original rhymes preserved.

These phenomena illustrate the prime importance of the translator's personal aesthetic orientation in ultimately determining aesthetic preferences and selection.

\subsubsection{Attitude toward recipients' response}

The attitude in question refers to how the translator respond to readers' needs, editors' requirements, critics' comments and the like.

M ost translators claim to care primarily about their readers' needs. There are still some who refuse to let readers' demands steer them away from pursuing fidelity to the original artistic and cultural significance. One representative translator of this kind is Lu Hsun, who claimed that he would "never deceive the readers" (see Qu 1931). Different attitudes towards the reader will no doubt encourage different strategic orientations, one target-oriented and the other source-oriented, and produce distinct versions of the text with different social and aesthetic values.

Editors' requirements are mainly of two types: one is obligatory and the other optional. O bligatory requirements include the instructions given to the translator that are meant to fulfill certain editorial intentions (such as rewriting or deleting certain passages for one reason or another). These translators normally have to obey. Optional requirements, on the other hand, take the form of technical suggestions, which vary from a general instruction to be target-oriented or source-oriented, to instructions to use a specific treatment for some individual passage. The translator may accept or reject these suggestions according to his or her own professional judgement.

Critics are another factor influencing the translator's social attitude. Historically, there are two main streams of translational criticism: the form-oriented who emphasize the artistic values of the translation and the content-oriented who are more concerned with conceptual values. Furthermore, the two streams of criticism are sometimes influenced by passing scholastic trends in literary criticism and linguistic development, so that critics' points of view are not always consistent. Some translators may be part of a prevailing trend and thus establish good relationships with critics, while others may insist on their own principles in spite of critics' opposition.

We can imagine an ideal translator who is faithful both to the writer and to the reader, and friendly to both editors and critics. In reality, however, very few approach 
this ideal. The great disparities in their needs and demands make it extremely difficult to satisfy all sides. In any case, it is up to the translator to decide how to cope with each of these requirements, and a strategy based of his or her attitude toward the recipients' response will be adopted and substantially affect the final product.

\subsubsection{Strategic attitudes}

Strategic attitude refers to how the translator responds to the predominant or traditional strategic orientations of his or her culture. The history of translation theory reveals that "there are certain concepts of translation that prevail at different times" (Bassnett 1992: 41). These "concepts" almost never give rise to a single, unified and consistent strategy to prevail at a given time. There are always at least two strategies available to deal with different aspects of translation, e.g., literalism vs. freedom, foreignization vs. domestication, writer-oriented vs. reader-oriented, archaizing vs. modernizing, etc. In the 1930s, for example, while Zhao Jingshen, a well known translator, claimed to be "SM OOTH even if WRONG," Lu H sun advocated "FAITHFUL even if NOT SM OOTH." Consequently, Zhao's principle led to his notorious translation of M ilky Way into niunai lu, i.e. cow-milky road. Obviously, anyone engaged in translating has to adopt a certain strategic stance in response to the strategic orientation of the period. And with the progress of human knowledge, translators' strategic selections become more and more mature. Finally, it should be noted that a translator's strategic attitude is also influenced to a great extent by his or her own outlook on language, literature, culture, and so on.

\subsubsection{Political and ethical attitudes}

Political and ethical attitudes can be described as the translator's active or passive response to the predominant political and ethical atmosphere in a given historicalcultural context. When the translator encounters an SL text with political or ethical viewpoints that do not conform to the TC political or ethical atmosphere, his or her own political or ethical attitudes will determine how it is treated. Those who agree with or feel forced to follow the established political or ethical norms of the TC would adapt their translation to these norms at the expense of the original political, ethical, and unavoidably, semantic significance. By contrast, translators who are defiant of or indifferent to the political or ethical norms of the TC will be more faithful to the SL text even if it were hostile or threatening to TC political or ethical values. Examples can be found in the German translations of Rip Van Winkle mentioned in 2.1.3, and Pan's and Lin's different translations of Joan Haste discussed in 2.1.4.

\subsubsection{Professional attitudes}

Professional attitudes simply refer to the translator's sense of professional responsibility towards his or her work. Mistranslation often results from the translator's irresponsible approach to work. Such a translator may display reluctance to make a careful and serious analysis of the original and to consult dictionaries, encyclopedias and experts for help in solving problems. Instead, the misinterpretation or misreading is simply written into the translation, sometimes even as obvious nonsense, other 
times in the guise of a misleadingly fluent and even elegant adaptation or paraphrase. Irresponsibility is attributable to various causes, such as unfair social and academic status, low pay, or tight deadlines. Generally, those who view their translation activity as an art, special interest or duty will be more responsible, while those who translate for money may be less so. Undoubtedly this sense of responsibility plays a crucial role in the process of translating and in the quality of the translation.

\section{CONCLUSION}

This discussion of the factors influencing the process of translating demonstrates just how complex a task translation is. Each of these factors can seriously interfere with the translator's judgement and selection, and ultimately materialize in one form or another in the final translation. A clear and systematic understanding of the existence and operation of these factors may help us grasp the complicated nature of translating and design effective strategies to counter negative influences.

\section{REFERENCES}

Bassn et t , S. (1992): Translation Studies, London and New York, Methuen.

Brown, G. \& G. Yul e (1983): Discourse Analysis, Cambridge, Cambridge University Press. Cat for d, J. C. (1965): A Linguistic Theory of Translation, Oxford, Oxford University Press.

Duan, Liancheng (1992): "An Appealing to Translators to Care about Foreign Publicity", An Anthology of Papers on Chinese-English Translation Techniques, Editorial Department of Chinese Translators Journal (Ed.), Beijing, China Foreign Translation Publishing Company, pp. 19-37.

Gentzl er , E. (1993): Contemporary Translation Theories, London and New York, Routledge. Gorl ée, D. L. (1994): Semiotics and the Problem of Translation, Amsterdam, Atlanta, G.A. Guan, Shijie (1995): Studies on Communications Across Cultures, Beijing, Peking University Press. H al I iday, M. A. K. (1985): An Introduction to Functional Grammar, London, Edward Arnold. Hall iday, M. A. K. \& R. Hasan (1976): Cohesion in English, London \& N ew York, Longman. Hul pke, E. (1991): "Cultural Constrains: a Case of Political Censorship", Kittel \& Frank (Eds), Interculturality and the H istorical Study of Literary Translations, Berlin, Erich Schmidt, pp. 7174.

Kit tel , H. \& A. P. Fr ank (Eds) (1991): Interculturality and the H istorical Study of Literary Translations, Berlin, Erich Schmidt.

Lad o, R. (1957): Linguistics Across Cultures, Ann Arbor, the University of M ichigan Press.

Leech, G. (1983): Semantics, Harmonthsworth, Penguin.

Liu, M iqing (1991): CE-EC Contrastive Studies and Translation, Nanchang, Jiangxi Education Publishing House.

Lu o, Xinzhang (1984): Essays on Translation, Beijing, Commercial Press.

M a, Yijun (1991): A Collection of Su Manshu, Guangzhou, Huachen.

$M$ a , Zuyi (1984): A Brief History of Chinese Translation, Beijing, China Translation Corporation. Nida, E. A. (1966): A Synopsis of English Syntax, The Hague, Moutin, 174 p.

- - (1979): Componential Analysis, The Hague, Paris, New York, M outon Publishers.

- - (1993): Language, Culture, and Translating, Shanghai, Shanghai Foreign Language Education Press.

N ida, E. A. \& C. R. Taber (1969): The Theory and Practice of Translation, Leiden, E. J. Brill.

Q u, Qiubai (1931): “Letter to Lu H sun”, Luo, Essays on Translation, Beijing, Commercial Press, pp. 265-273.

Sapir , E. (1956): Culture, Language and Personality, Berkeley \& LosAngeles, University of California Press. 
Saussure, F. de (1960): Course in General Linguistics, Tr. Wade Baskin, London, Peter Owen Limited.

Shen, Dan (1989): “Literalism: Non 'Formal Equivalence'”, Babel, vol. 35, nº 4.

- - (1995): Literary Stylistics and Fictional Translation, Beijing, Peking University Press.

Su, Manshu (1991): Les M isérables, tr. 1903, Ma (Ed.), A Collection of Su Manshu, vol. 2, Guangzhou, Huachen.

Tan, Zaixi (1990): “On Semantic Contrast in Translating”, Yang \& Li (Eds), An Anthology of Contrastive Studies Between English and Chinese, Shanghai, Shanghai Foreign Language Education Press, pp. 128-139.

Yang, Zijian \& Ruihua Li (Eds) (1990): An Anthology of Contrastive Studies Between English and Chinese, Shanghai, Shanghai Foreign Language Education Press.

Yin, Bansheng (1907): "On the Two Versions of Joan H aste", Game World, Issue 11, Shanghai. 